\title{
As Práticas Editoriais e de Publicação das revistas científicas portuguesas de Ciências Sociais
}

\author{
Maria Manuela Tavares de Matos Cardoso \\ Universidade Lusíada do Porto (Portugal)
}

\section{Resumo}

O presente artigo tem como principal objectivo a análise das práticas editoriais e de publicação de 43 revistas científicas portuguesas de Ciências Sociais, a partir das declaraçôes que estas revistas expressam nas suas próprias páginas. Este estudo expõe uma experiência de pesquisa do grau de cumprimento, por parte destas revistas, de parâmetros normativos internacionais relativos à apresentaçấo de artigos em publicaçóes periódicas, com o fim de ao estabelecer um perfil destas revistas e dar um primeiro passo para melhorar a sua qualidade editorial, na medida em que a normalização é verdadeiramente um factor indispensável no sucesso do processo de transferência da informação científica. Num primeiro momento procedeu-se a uma heteroavaliação das revistas e examinou-se, através das suas instruçóes para os autores, o cumprimento por parte de cada uma delas, de 58 parâmetros normativos. E, posteriormente, com o objectivo específico de identificar com maior profundidade as políticas de Peer Review das revistas em análise, realizou-se complementarmente, uma autoavaliaçáo destas através do envio de questionários aos 43 directores destas publicaçôes. O perfil característico destas é o de revistas adultas, auspiciadas na sua maioria por instituiçôes universitárias, publicadas fundamentalmente em Lisboa, de periodicidade ampla (semestral/trimestral) e existe uma discrepância considerável entre aquilo que as revistas dizem ser as suas prática e aquilo que são as práticas efectivas através das instruçôes para os autores. Em geral, estas revistas não se ajustam às normas internacionais de apresentação formal de publicaçôes periódicas, apresentando um fraco padrão na qualidade normativa e do seu processo editorial. O grau de normalizaçáo, em 58 parâmetros analisados nas 43 revistas portuguesas, é de $28 \%$. Conclui-se este estudo oferecendo uma série de medidas que levem ao aperfeiçoamento, para que estas possam entrar num novo ciclo de vida: profissionalizadas e internacionalizadas.

\begin{abstract}
This article's main goal is to analyze the editorial and publishing practices on 43 scientific Portuguese magazines on Social Sciences, based upon the declarations published on the pages of the studied magazines. This study expresses a research of the level of accomplishment achieved by these magazines of international normative parameters regarding the publishing of articles in periodic publications, in order to establish a profile of these magazines and take a first step to improve their editorial quality, considering that normalization is truly an indispensable factor to assure the success on the process of scientific information transfer. First, the study evaluates the magazines by examining the accomplishment of the 58 normative parameters provided by the magazine to their authors. Then, in order to identify more accurately the Peer Review Policies of the magazines under study, inquiries were sent to the 43 directors of these publications so they could perform their own self evaluation. The common profile of these magazines is that they have an adult target, most of them are sponsored by universities,
\end{abstract}


they are mainly published in Lisbon, with a wide range of periodicity (semester/trimester) and they reflect a considerable gap between their practices and the instructions given to the authors. In general, these magazines do not conform to the international norms of periodical publications' publishing and they show a low level of normative quality on their editorial process. The normalization level achieved in the 58 analyzed parameters on the 43 Portuguese magazines is $28 \%$. Therefore, this study ends suggesting a series of measures that can improve the magazine's normative quality, leading them to a new life cycle: the improvement of professional skills and internationalization.

\section{Introduçáo}

As revistas científicas são na prática totalidade das ciências, entre os múltiplos canais formais (livros) e informais (comunicaçôes em congresso, pareceres científicos e técnicos, correspondência postal ou electrónica, grupos de notícias ou foros electrónicos), o principal meio de comunicação científica (Delgado López-Cózar, Ruiz, \& Jiménez Contreras, 2007). Náo são somente um canal privilegiado para dar a conhecer os resultados de investigação mas também actuam como meio de informação imprescindível. É por tal motivo que as revistas se converteram em objecto de investigaçáo. Não foram poucos os trabalhos que procuram conhecer quais são as práticas de publicação e políticas editoriais (Coe \& Weinstocks, 1967; Beyer, 1978; Peters \& Ceci, 1982; Godlee \& Jefferson 1999; Weller, 1990; Colaianni, 1994; Wilkes \& Kravitz, 1995; Baker, 2002; Freda \& Kearney, 2005) o seu ajuste às normas nacionais e internacionais de publicação científica (Delgado López-Cózar 1997, 1998, 1999). Em Portugal, e partindo da experiência profissional, apesar de haver um crescente número de revistas científicas, por área científica, até ao momento, e de acordo com informação dada pela Coordenadora do sistema da LATINDEX em Portugal (Cardoso, 2007) não existem estudos publicados sobre a nossa temática de investigação ${ }^{1}$. É de salientar que, a Fundaçâo para a Ciência e a Tecnologia (FCT) ${ }^{2}$ tem investido muito trabalho junto dos editores para que este móbil seja compreendido por estes e que por consequência seja atingido. De acordo com Rosário Costa (2007), a comunicação estabelecida com os editores baseia-se numa análise prévia que a FCT faz às revistas, sempre na óptica da qualidade editorial. Assim, o trabalho da FCT realiza-se em duas etapas: por um lado, quando as revistas são seleccionadas imediatamente para o Catálogo significa que cumprem os critérios mínimos exigidos pelo LATINDEX, tendo desta forma a missão de informar, posteriormente, os respectivos editores da sua realidade; por outro lado, os editores das revistas que não cumprem com os requisitos mínimos são contactados pela FCT, no sentido desta os informar sobre o sistema LATINDEX e apresentando-lhes o diagnóstico da revista em questão e, por fim, cabe-lhes o papel

${ }^{1}$ De acordo com informação enviada por e-mail pela Coordenação do LATINDEX em Portugal (Gabriela Lopes da Silva, da Fundaçấo para a Ciência e a Tecnologia).

${ }^{2}$ Os incentivos concedidos pela FCT para a promoção das revistas é realizada em duas vertentes: se por um lado, a FCT oferece apoio financeiro para a publicação de revistas nacionais e promove a participação destas no sistema LATINDEX; por outro lado, são conhecidos os vários incentivos no sentido de se publicar a produção científica portuguesa em revistas científicas internacionais. 
de explicar aos editores destas publicações a necessidade que existe em melhorá-las para que estas possam, a curto ou médio prazo, serem aceites e inseridas no Catálogo LATINDEX. Assim, o êxito da acção da FCT tem vindo a crescer, no entanto, tudo depende da receptividade dos editores às transformaçóes necessárias e propostas. $\mathrm{O}$ balanço que pode efectuar é muito positivo e expressivo, no sentido em que no ano de 2002 (Julho), constavam no Catálogo 11 revistas portuguesas e em 2009 (Julho), já são 113. Assim, é já muito discutível se será exequível e desejável manter este aumento. Por outro lado, é importante mencionar que a FCT, para além da promoção das revistas científicas portuguesas, também o faz em relação às revistas internacionais, no sentido em que esta instituição avalia as publicaçóes em revistas internacionais, sendo um dos parâmetros da avaliação plurianual das unidades de I\&D. A FCT, prioritariamente, galardoa as unidades de I\&D que publicam os resultados dos seus trabalhos em revistas de circulação internacional. Desta forma, a FCT apresenta uma visão que já não é a curto prazo mas a longo, trabalhando com os editores nacionais para que num futuro possamos ter revistas científicas portuguesas com difusão internacional e de referência. Paralelamente ao sistema LATINDEX e à promoção das revistas científicas portuguesas e, consequentemente, à melhoria da qualidade editorial das revistas portuguesas, encontra-se em desenvolvimento uma plataforma electrónica, composta por revistas científicas portuguesas, em livre acesso, a toda a comunidade científica e público em geral.

Assim, o Observatório da Ciência e do Ensino Superior (OCES) ${ }^{3}$, em parceria com um conjunto de outros países da América Latina e Espanha ${ }^{4}$, aderiu em 2001 à plataforma SciELO - Scientific Electronic Library Online ${ }^{5}$. Esta plataforma é um modelo para a disponibilização electrónica de uma colecção seleccionada de periódicos científicos. Este projecto SciELO teve a sua origem no Brasil em 1998 e é o produto da cooperação entre a FAPESP - Fundação de Amparo à Pesquisa do Estado de S. Paulo e BIREME - Centro Latino-americano e do Caribe de Informação em Ciências da Saúde, instituiçóes nacionais e internacionais relacionadas com a comunicação científica e editores científicos. O grande objectivo do OCES ao desenvolver o projecto SciELO Portugal ${ }^{6}$ consiste em promover, via Internet, as revistas científicas portuguesas de qualidade e difundir mundialmente a produção científica nacional, que fica acessível, de forma gratuita e em texto integral, a toda a comunidade científica nacional e internacional. Esta colaboração do OCES nesta plataforma poderá, a longo prazo, contribuir para

\footnotetext{
${ }^{3}$ O OCES é um órgão do MCTES (Ministério da Ciência, Tecnologia e Ensino Superior) que monitoriza o ensino superior e a actividade tecnológica e científica em Portugal (OCES, 2007).

4 Países aderentes à plataforma SciELO: Brasil, Chile, Cuba, Espanha, Costa Rica, México, Venezuela, Colômbia, Argentina, Peru e Portugal.

5 SciELO (SciELO, 2007a) Esta plataforma é um modelo para a disponibilizaçáo electrónica de uma colecção seleccionada de periódicos científicos. O projecto SciELO é o produto da cooperação entre a FAPESP - Fundação de Amparo à Pesquisa do Estado de São Paulo e BIREME - Centro Latino-Americano e do Caribe de Informação em Ciências da Saúde, instituiçôes nacionais e internacionais relacionadas com a comunicação científica e editores científicos.

${ }^{6}$ SciELO Portugal (SciELO Portugal, 2007a). Esta plataforma electrónica está acessível através do URL seguinte: http://www.scielo.oces.mctes.pt/. Concomitantemente, permite ainda, o acesso através do SciELO. org, a toda a colecção de revistas científicas disponíveis nesse Sítio.
} 
o desenvolvimento da qualidade dos conteúdos das revistas e para o cumprimento da linha editorial das revistas científicas portuguesas incluídas no SciELO. O site SciELO Portugal ficou disponível a 13 de Março de 2005, estando já disponível um grupo de revistas seleccionadas e para o cumprimento da metodologia SciElO, foi constituído o Comité Consultivo SciELO Portugal, que iniciou funçóes em 2006, em Lisboa, tendo já definido e aprovado o respectivo Regulamento Interno de funcionamento. O presente estudo pretende apresentar, uma reflexão e, paralelamente, uma primeira aproximação da situação formal das revistas como principais órgáos de difusão e comunicação do conhecimento certificado.

\section{Material e métodos}

Trata-se de um estudo seccional descritivo de 43 revistas científicas portuguesas de Ciências Sociais (CS). Foram utilizadas as chamadas Normas de publicação das revistas, Instruçóes para os autores ou Instruçóes para apresentaçâo de manuscritos e, em geral, a informação que oferece a revista nas suas próprias páginas. Foram considerados 58 parâmetros sobre práticas editoriais e de publicação que são comprovados em cada uma das 43 revistas de CS, os quais encontram-se estruturados numa Folha de Recolha de dados apresentada no Anexo 2 (daqui para frente designada por FRD) extraída dos critérios de avaliação de revistas proposta por Delgado López-Cózar et al. (2007). A FRD estrutura-se em três colunas com as seguintes designaçóes: a) Revistas (título da revista); b) Avaliação (avalia-se um parâmetro com o emprego dos provérbios "SIM" e "NÃO", ou seja, confirma-se ou não a presença de um parâmetro nas declaraçóes expressas nas próprias páginas da revista, nas instruçóes aos autores); e c) Conteúdo (se for comprovado determinado na revista a avaliação é positiva ("SIM") e imediatamente transcreve-se literalmente as declaraçôes expressas nas páginas da revista. Por exemplo, ao analisar o parâmetro "Recepção e Agradecimento", não obstante só vamos comprovar se efectivamente a revista inclui informação sobre este parâmetros, mas também é necessário no caso da comprovação ser "SIM" validar essa avaliação na coluna denominada "Conteúdo" com informação retirada da revista. Assim, num primeiro momento, após a aplicação das FRD às revistas, ou seja, a caracterização do cumprimento dos 58 parâmetros normativos das FRD, procedeu-se ao tratamento desses dados, calculando a percentagem dos parâmetros cumpridos ("SIM") e não cumpridos ("NÃO") em cada revista analisada, por área de conhecimento. Optou-se por proceder ao agrupamento destas revistas em 10 grandes grupos ou macro áreas pertencentes a áreas do conhecimento das CS: Antropologia; Ciência Política; Comunicação; Educação; Documentaçáo; Economia; Geografia; Multidisciplinares; Psicologia e Sociologia. Este agrupamento adoptou-se atendendo, basicamente, a dois critérios: afinidade de áreas de conhecimento e evitar demasiada disparidade no tamanho dos grupos. Para o tratamento dos dados das FRD e a geração de representaçôes gráficas utilizamos a folha de cálculo Excel 2003. 


\section{Resultados e discussão}

Será importante, desde já, apresentar o perfil característico das revistas estudadas:

1. Apesar de serem poucas as revistas que exibem a sua antiguidade (6), a análise conclui que se está perante revistas adultas, a maior parte destas têm mais de 20 anos de vida. $\mathrm{Na}$ sua maioria, estas revistas tiveram um arranque significativo a partir das décadas de 60, 70 e, principalmente, nos anos oitenta; 2. Encontram-se auspiciadas por instituiçôes universitárias (30), associações/sociedades profissionais (6) ou editoras nacionais (7) e internacionais (1); 3. Existe uma concentração das revistas em regióes periféricas, sendo publicadas fundamentalmente em Lisboa (32) e as restantes em cidades como o Porto (4), Coimbra (6) e Minho (1). A concentração das revistas à volta de cidades, principalmente, de Lisboa e Coimbra, justifica-se por ambas terem as duas universidades mais antigas e onde ao longos dos anos se terem estabelecido e cristalizado grandes grupos de profissionais e investigadores; 4. Têm, na sua maioria, como organizaçóes patrocinadoras a sua própria editora, que se assume como a responsável intelectual da publicação das revistas; 5. A sua periodicidade é ampla, sendo uma situação característica das revistas de ciências sociais, ou seja, são predominantemente semestrais (17), trimestrais (6), quadrimestrais (5) e anuais (3).

\subsection{Análise geral das políticas editoriais e práticas de publicação}

Em linhas gerais pode afirmar-se que, as revistas portuguesas de CS analisadas, oferecem muito pouca informação sobre as suas práticas editoriais e de publicaçấo (Fig. 1). É preocupante a ausência de informação sobre a política editorial seguida pela revista (se a revista dá permissão para haver reprodução de informação protegida pelo direito de propriedade intelectual; a transferência de direitos de exploração do artigo; a não devolução de manuscritos recusados; e, sobre a política de autoria, quase todas as revistas não fixam quais são os critérios que devem cumprir os assinantes de um artigo para serem considerados autores do mesmo e as respectivas mediadas para assegurar que se cumpram (declaraçóes assinadas, etc.), sobre o sistema empregue pela revista para a avaliação dos manuscritos que recebe (peer review) ou sobre a forma de apresentar os originais à revista.

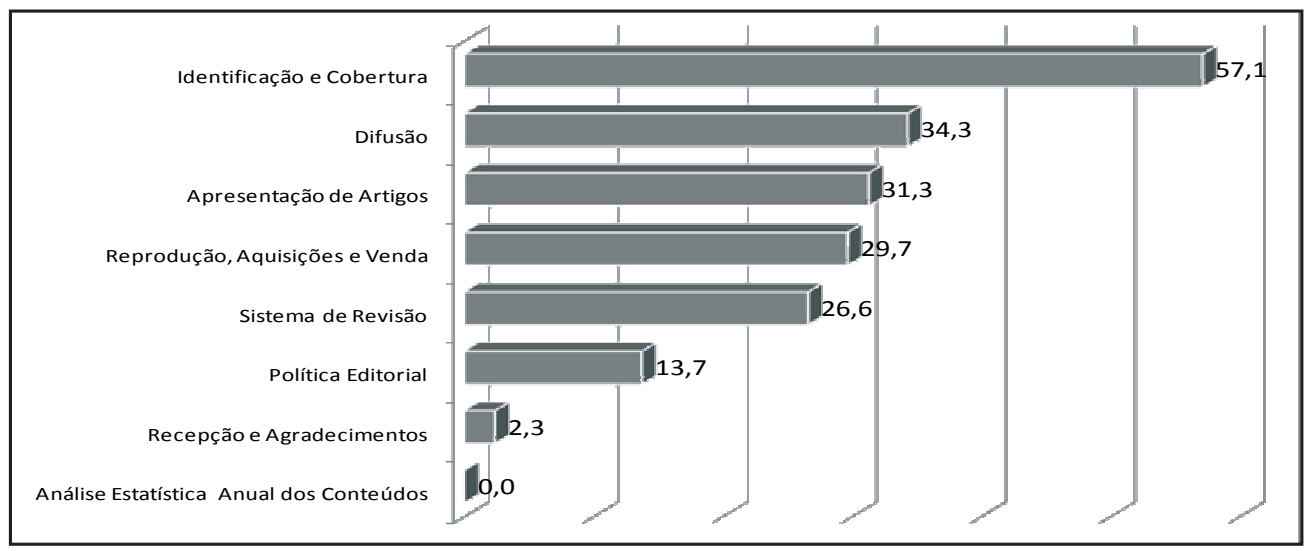

Fig. 1 - Ajuste normativo por bloco 
Existem algumas revistas que não apresentam tão-pouco instruçôes para os autores, ou seja, não informam os autores como devem apresentar os seus trabalhos, visto que não declaram nada. Por outro lado, esta ausência informativa diz muito sobre a escassa normalização destas e reflecte uma má qualidade formal, como meio de comunicação, das revistas. Esta situação habitualmente ocorre nas revistas de Ciências Sociais, ao contrário, nas Ciências Naturais, ocorre tudo de maneira antagónica. A explicação apresentada pelos estudiosos é sociológica e filosófica, ou seja, existem dois discursos científicos devido à natureza das disciplinas: um muito normalizado e homogéneo (Ciências Naturais e Experimentais) e outro muito pouco normalizado e muito heterogéneo (Ciências Sociais e Humanas).

\subsubsection{Recepção e Agradecimento}

O primeiro bloco analisado foi o da Recepção e Agradecimentos que, por ter sido explicitado por uma única revista surge como um dos aspectos menos tido em consideração nas práticas editoriais dominantes, com um grau de cumprimento de $2,3 \%$.

\subsubsection{Política Editorial e de Publicação}

No segundo bloco foram analisados 11 parâmetros e todos eles são escassamente referenciados pelas revistas (Anexo 1).

Tabela 1 - Informação oferecida sobre a política editorial e de publicação de 43 revistas portuguesas de Ciências Sociais

\begin{tabular}{|l|l|l|}
\hline \multirow{2}{*}{ Parâmetro } & \multicolumn{2}{l|}{ Revistas } \\
\cline { 2 - 3 } & $\mathrm{n}$ & $\%$ \\
\hline Declaração de originalidade (não se publicou anteriormente) & 2 & 4,7 \\
\hline Declaraçáo de não envio simultâneo a outras revistas & 4 & 9,3 \\
\hline Declaração de autorização por cada um dos assinantes de um artigo & 0 & 0,0 \\
\hline Declaraçáo de conflitos de interesse & 0 & 0,0 \\
\hline Permissão de publicar por parte da instituição que financiou a investigação & 2 & 4,7 \\
\hline Permissão por ter reproduzido informação protegida por direito de propriedade intelectual & 8 & 18,6 \\
\hline Transferência de directos de exploração do artigo & 7 & 16,3 \\
\hline Aceitação de correr com gastos derivados do processo de revisão ou de impressão & 1 & 2,3 \\
\hline Compromisso ou náo com opinióes & 25 & 58,1 \\
\hline Não devolução de artigos recusados & 12 & 27,9 \\
\hline Política de autoria & 4 & 9,3 \\
\hline
\end{tabular}

Num total de 43 revistas, é muito baixo o ajuste normativo (13,7\%) que apresenta este bloco, sendo o parâmetro com maior grau de cumprimento denominado "Compromisso ou não com opiniôes" com 58,1\%. 


\subsubsection{Sistemas de Revisão}

O Peer Review (em português designado por revisão pelos pares), que remonta à controvérsia entre Newton e Leibniz sobre a invenção do cálculo infinitesimal, de acordo com H. Hellman (Hellman, 1998), tem constituído um dos pilares da construção da Ciência Moderna. Assim, se confiamos na qualidade das revistas científicas fazemo-lo, em parte, pelo processo de avaliaçáo dos originais que se publicam nelas. Nas palavras de López-Cózar (Delgado López-Cózar, 2001), apesar dos defeitos que este tem vindo a evidenciar (é lento, custoso, desperdiçador do tempo da comunidade científica, subjectivo, propenso ao ambíguo, permite abusos, é incapaz de detectar fraude, o plágio e a publicação duplicada, não pode garantir a validade externa dos trabalhos) o processo de revisáo pelos pares tem sido considerado como o eixo fundamental da publicação científica válida e de qualidade.

Neste bloco pretendeu-se analisar os sistemas de revisão e avaliação empregues por parte das distintas revistas em análise para controlar a qualidade dos originais. Com os parâmetros deste bloco pretendemos determinar se uma revista avalia os originais que recebe ou não. Verificaremos, mais à frente, que se uma revista não avalia os originais que recebe não possui nenhum sistema de revisão pelos pares de manuscritos (o caso das revistas sem instruçóes para os autores).

Sáo muitas as que declaram que avaliam os originais que recebem. Náo obstante, estas não apresentam qualquer explicação nas suas instruçóes para os autores sobre os seus sistemas de revisão empregues para controlar a qualidade dos manuscritos. Também, a maior parte destas declara que emprega a revisão editorial e somente algumas afirmam aplicar o sistema de revisáo por pares.

Por outro lado, mais de metade das revistas declara que implementa a revisão editorial em todos os manuscritos recebidos $(62,8 \%)$, sendo os artigos submetidos a revisáo por parte dos membros da direcção da revista ou do Conselho de Redacção ou da Comissão Editorial, imediatamente depois de receber os originais. Também a maior parte das revistas que, declara que executa a revisão editorial $(51,2 \%)$, não recorre à revisão pelos pares $(41,9 \%)$. Concluímos que, a informação dada pelas revistas relativamente a execução da revisão editorial dos originais é muito deficitária, declarando a grande maioria das revistas que, a apreciação preliminar e/ou decisão final de aceitar ou não o original é sempre da competência da direcção da revista. E, finalmente, relativamente à revisão pelos pares e, de acordo com López-Cózar e Ruiz Pérez (Delgado López-Cozar \& Ruiz Pérez, 2003) o sistema de revisão pelos pares pode classificar-se atendendo a dois critérios: 1) Procedência dos revisores: os revisores podem ser internos ou externos; e 2) Anonimato do processo de revisáo: de acordo com a identidade de autores e revisores o sistema de arbitragem admite 3 modalidades (o sistema cego, o sistema de duplo cego e o sistema aberto). No entanto, as revistas que declaram que realizam avaliação pelos pares, são poucas as que informam sobre a modalidade do respectivo processo. Assim, todas revistas que informam sobre essa modalidade, recorrem ao Anonimato do processo de revisão, modalidade de sistema cego.

No que toca aos parâmetros "Número de revisores", concluímos que os resultados são mais uma vez muito negativos, pois somente 7 revistas $(18,6 \%)$ declaram nas suas instruçóes para os autores o número habitual de revisores empregues por estas na avaliaçáo dos seus manuscritos. É assinalável, ainda, nestas revistas o facto destas 
empregarem na avaliação dos seus manuscritos 2 revisores, o que segundo alguns autores é o número mais ajustado?

Quanto ao parâmetro "Critérios de revisão", pretendeu-se neste estudo avaliar se as revistas declaram ou não, quais são os critérios que têm em conta para aceitar os artigos. Sabendo previamente que este tipo de critérios pode variar dependendo da natureza e cobertura da revista, considerámos previamente os 5 seguintes critérios: 1. Originalidade: totalmente original, confirmação valiosa, repetição e resultados conhecidos; 2. Actualidade e novidade; 3. Relevância na sua dupla vertente de utilidade: aplicabilidade dos resultados para a resolução de problemas concretos e significado, no sentido de avanço do conhecimento científico; 4. Fiabilidade e validade científico: qualidade metodológica ajustada; 5. Apresentaçâo: boa redacção (claridade, brevidade e precisão), boa organização (coerência lógica) e boa apresentação material.

A maioria não declara qualquer informação sobre estes critérios, sendo o grau de cumprimento de $2,3 \%$.

O parâmetro "Prazos de Revisão" teve um grau de cumprimento de 9,3\%. As revistas portuguesas deveriam publicar guias e instruçóes que remeteriam aos seus revisores e que conteriam informação sobre itens diversificados, tais como os prazos de revisão, etc. e não o fazem.

\subsubsection{Identificação e Cobertura}

A Identificaçáo e cobertura foi o bloco com a taxa de cumprimento mais elevada (57, $1 \%)$, isto é, foi o bloco relativamente ao qual, no seu conjunto, as revistas analisadas satisfizeram um maior número de parâmetros.

O idioma mais utilizado é o português e perante revistas publicadas em dois idiomas, predomina o português-inglês.

\subsubsection{Reprodução, Aquisições e Venda}

Sobre questôes relacionadas com a reprodução, aquisiçôes e venda, as revistas somente oferecem informação sucinta de alguns aspectos, a saber: quase nenhuma faz menção expressa sobre a sua política de protecção de propriedade intelectual; mais de metade, apresenta informação sobre a aquisição e subscrição completa, números soltos ou atrasados, individual ou institucional, país de origem e estrangeiro, destacando-se o facto de quase todas (42) apresentarem unicamente o preço para a subscrição da edição impressa, o que significa que, à partida, é muito escasso o grau de edição em formato digital das revistas portuguesas de CS, tendo, ainda, a maior parte delas uma circulação eminentemente impressa. Neste bloco foram analisados 4 parâmetros e o ajuste normativo é mais uma vez muito baixo (29, 7\%).

\footnotetext{
${ }^{7}$ Apesar de não existir uma norma relativamente ao número de revisores empregues por uma revista, existem autores tais como $O^{\prime}$ Connor e Bishop que consideram que o número que se tem considerado mais adequado é o de dois revisores.
} 


\subsubsection{Difusão}

Numa época em que os meios de informação e o alcance da mesma são a chave para o desenvolvimento científico, a difusão do conhecimento é outro dos elementos importantes para a avaliação de revistas técnico-profissionais. Segundo Román Róman (Román Róman, 2001) a visibilidade de uma revista pode considerar-se a distintos níveis, que podemos classificar em difusáo directa (por exemplo, tiragem, número de subscritores e presença em catálogos e bibliotecas) e indirecta (por exemplo, citação em bases de dados, directórios e presença na Internet). E, de acordo com Delgado López-Cózar (Delgado López-Cózar, 2002) o grau de circulação de uma revista depende da tiragem, subscriçôes e intercâmbio. Relativamente à análise efectuada à visibilidade nacional e internacional (difusão) destas publicaçôes, estas oferecem a seguinte informação: comprovou-se que a maior parte não são indexadas em bases de dados, o que significa que têm uma circulação, visibilidade e acessibilidade muito reduzida; é baixo, também, o número de revistas (18) que declaram a sua tiragem; a maior parte (38) não declara disposição para realizar permuta ou intercâmbio com outras publicaçôes nacionais e internacionais; e, por último, mais de metade (27) recebem subvenções por parte de organismos públicos e/ou privados, sendo predominante o financiamento de origem público (orçamento de estado e quadro comunitário português), cujos principais agentes deste investimento são a Fundação para a Ciência e Tecnologia (FCT) e o Instituto Português do Livro e da Leitura (IPLB).

\subsubsection{Análise Estatística Anual dos Conteúdos}

Comprovou-se que nenhuma revista apresenta uma secção com informação estatística anual acerca do seu processo editorial ou seja, número de trabalhos recebidos e publicados, taxas de aceitação e recusa e tempos de publicação (demoras).

\subsubsection{Apresentaçáo de Artigos}

Por último, analisámos os seguintes 20 parâmetros que constituem o último bloco da FRD, relativo à Apresentação de artigos: Remissão a normas de apresentação ou manual de estilo (14,0\%); Informático (62,8€); Papel (60,5\%); Estrutura Física (44,2\%); Título do artigo (27,9\%); Nome e apelidos completos do (s) autor (es) (30,2 \%); Filiação Professional autor (es): Cargo e organismo (27,9\%); Reconhecimento de bolsas ou apoios financeiros $(0,0 \%)$; Direcção postal completa $(18,6 \%)$; Outros meios de telecomunicação ou contacto com os autores (11,6\%); Nos artigos assinados por vários, indicar o responsável da correspondência (9,3\%); Tipo (Indica Se é estruturado ou não) (0,0\%); Extensão (Número de palavras) (67,4\%); Palavras-chave: Número e remissão a um tesauro (44,2\%); Estrutura para trabalhos originais. Adopta modelo IMRYD (2,3"); Explicação do conteúdo de cada parte, seu estilo e características (2,3\%); Agradecimentos (4,7\%); Sistema de citação e formato de descrição bibliográfica $(81,4 \%)$; Tabelas $(53,4 \%)$; e Ilustraçóes $(62,8 \%)$. 
Analisou-se que $80 \%$ das revistas não orientam os autores para a consulta de normas de apresentação ou manuais de estilo que são seguidos pela respectiva revista. No que toca a questóes relacionadas concretamente com $o$ texto, estas apresentam muitas anomalias, tais como: quase nenhuma apresenta indicaçôes a respeito da exigência dos autores apresentarem os originais de com acordo com a estrutura IMRYD (Introdução, Método, Resultados e Discussão); são muito poucas as que apresentam directrizes acerca de qual a informação que deve conter cada parte do texto, o seu estilo e características; e, em relaçáo aos agradecimentos que os autores queiram fazer nos seus manuscritos, as revistas não apresentam qualquer orientação quanto à forma de os dispor. Quase todas oferecem informação aos autores sobre o sistema de citação e a forma de redigir as referências bibliográficas e, ainda, oferecem pautas exemplificativas de referências bibliográficas dos vários tipos de documentos. O sistema de citação textual mais adoptado e de aplicação consistente e uniforme é o sistema de autor - ano, também conhecido pelo sistema Harvard, ou seja, as fontes são citadas no texto, normalmente entre parêntesis, pelo primeiro apelido do autor seguido do ano de publicação do documento citado. Neste caso, somente 23,2\% (10) especifica aos autores qual a norma que devem adoptar para redigirem as citaçôes no manuscrito. Assim, destas 23,2\% das revistas, apenas $11,6 \%$ remetem, especificamente, os autores para as normas nacionais, as denominadas de Normas Portuguesas. Apesar de 81,4\% apresentarem directrizes aos autores de como estes devem redigir e apresentar as referências bibliográficas dos manuscritos, sendo grande parte destas acompanhadas de pautas exemplificativas. A maioria apresenta pautas exemplificativas de referências bibliográficas $(53,5 \%)$.

\subsection{Resultados por Área do Conhecimento}

Pode apreciar-se, seguidamente, as diferenças nas práticas editoriais das revistas por área do conhecimento.

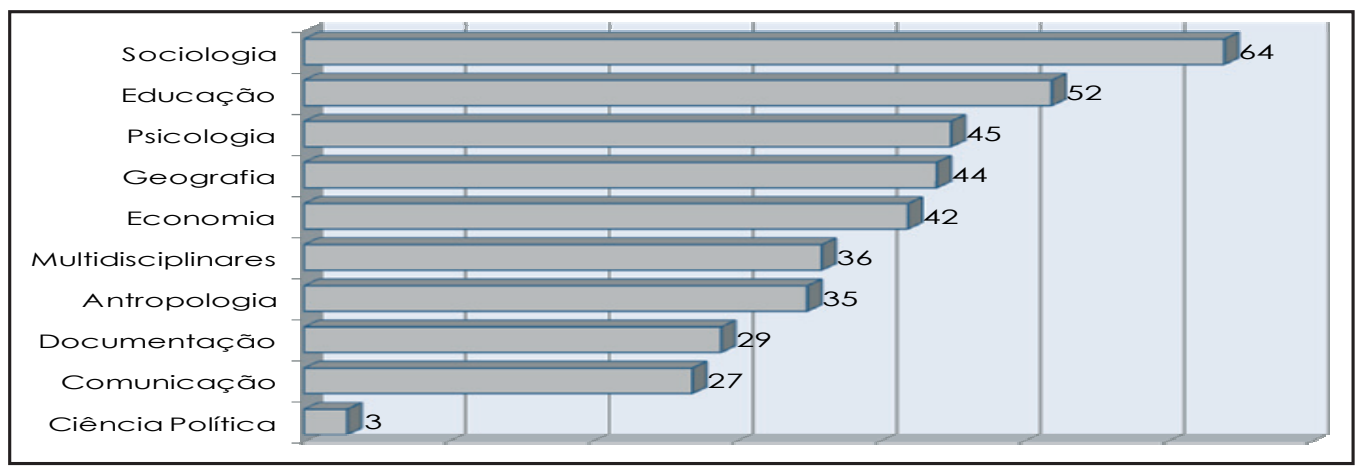

Fig. 2 - Nível de cumprimento global dos parâmetros, por área de conhecimento

Através do Fig. 2 observa-se que no universo total de revistas, a área da Sociologia é aquela que apresenta um nível de cumprimento global mais elevado, i.e., mais de metade dos itens relativos aos diversos parâmetros são explicitados pelos 
títulos desta área do conhecimento. Seguidamente perfilam-se os títulos de Educação e Psicologia que apresentam índices vizinhos de cumprimento dos parâmetros.

\section{Conclusóes}

Somos conscientes de que as revistas portuguesas constituem um fenómeno de estudo de dimensôes institucionais e sociais, amplas e complexas e foi no âmbito da avaliação das revistas científicas que, por um lado, se procedeu à analise das práticas editoriais das revistas portuguesas na área das CS, expondo uma experiência de pesquisa e, por outro, promover os estudos de avaliação destas revistas como prioridade na investigação. Em geral, as revistas portuguesas nesta área necessitam de ser objecto de uma profunda reflexão e consequente revisão, tanto nos seus aspectos formais, como também será necessário reexaminar os aspectos relativos á gestão e política editorial. É imprescindível, realizar estas reformas o quanto antes, para que estas publicaçôes possam sair da situaçáo endógena, e assim alcançar uma maior profissionalização e visibilidade, sendo possível, ao mesmo tempo, abri-las à colaboração de especialistas de outras regióes e países. Assim, a partir da análise realizada no sistema LATINDEX (LATINDEX, 2007), parece-nos comum a várias áreas do conhecimento das CS que, realmente, embora haja uma proliferaçáo de revistas nacionais e esforço por parte de cada instituição para publicar nas suas revistas artigos dos seus investigadores institucionais e da sua área geográfica (postura endógena), muitas vezes fazem-no sem terem qualquer segurança de sustentáculo económica e científico. Neste contexto, parece-nos sensato que se combata a multiplicação de revistas, adoptando desta maneira, uma política de união de esforços, como estratégia para fomentar qualidade a estas revistas. Estes novos planos editoriais devem ter na base a pretensão de qualidade fundamentada, na ideia de que o que se escreve e comunica nestas publicaçóes interessa a toda uma comunidade científica, não só nacional mas, acima de tudo, internacional, desde que contenha qualidade.

Apesar da situaçáo das práticas editoriais destas ter uma tendência para melhorar e, mesmo inovar, nos últimos anos com a participação destas em projectos internacionais e inovadores (SciELO Portugal e LATINDEX), se as compararmos com as revistas dos nossos países vizinhos, como por exemplo a Espanha, ou mesmo com as da área das ciências exactas portuguesas, imediatamente reconhecemos que ainda existe um grande caminho a percorrer para nos aproximarmos das suas boas práticas editoriais. Perante tal panorama, o trilho a seguir terá que ser sem atalhos e, inevitavelmente, ousamos em dizer que as políticas editoriais e de publicação das revistas científicas portuguesas carecem urgentemente de entrar numa nova etapa. Assim, olhando para um futuro melhor para estas publicaçôes, e tal como recomendam Delgado López-Cozar et al. (2007) para as revistas espanholas, as revistas portuguesas de CS deverão nos próximos anos empreender um aperfeiçoamento, adoptando as seguintes medidas: 1. As revistas teráo que ter consciência da obrigatoriedade de apresentar de forma detalhada as suas Normas de publicação da revista, Instruçôes para os autores, ou Instruçôes para a apresentação de manuscritos e de melhor zelarem pela apresentação destas com exactidão e detalhe pois estas constituem uma das secçóes mais importantes das mesmas; 2. Melhorar a difusão das normas nacionais e internacionais de publicaçáo científica relativamente 
à apresentação formal; 3. Fazer cumprir, de forma rigorosa, as normas nacionais e internacionais de publicação no que respeita à apresentação de artigos; 4. Exigir aos autores uma carta de apresentação, na qual o autor deve justificar a originalidade do seu trabalho e onde este deve explicar as novidades que este apresenta para o avanço da ciência; 5. Declarar com transparência a política editorial e de publicaçáo da revista em relação a aspectos muito importantes tais como, recepçáo e agradecimento do manuscrito, envio simultâneo a outras revistas, autorização por cada um dos autores que assinam um artigo, conflitos de interesses, permissão por parte da instituição que financiou o trabalho, reprodução da informação protegida por direito de propriedade intelectual, transferência de direitos de exploração do artigo, gastos derivado do processo de revisão ou de impressão, compromisso ou não opiniôes, devolução ou não dos manuscritos recusados e política de autoria; 6 . Devem definir bem o que é revisão editorial e o sistema de revisão pelos pares, não sendo suficiente por parte destas declararem possuir uma revisão editorial, mas também o sistema de revisão e os critérios de avaliação dos artigos devem ser descritos da forma o mais transparente possível, a partir dos seguintes termos: sistema de arbitragem científica aplicada (anónima - cego ou duplo cego), externa ou confidencial; o número de revisores a empregar por artigo; como se realiza a selecção dos revisores; os critérios que os revisores terão que ter em conta na revisão dos artigos; informarem os revisores dos prazos de revisão; e, publicarem guias e instruçôes de avaliação empregues pelos revisores. Assim, no imediato, recomendamos:

- Implementar a revisão editorial sistemática a todos os artigos recebidos, ou seja, que todos os artigos adquiridos pelas revistas, sem haver excepção, sejam submetidos à revisão por parte de um membro do Conselho de Redacção da revista. Assim, que se realize uma revisão anónima editorial de todos os artigos por pares seleccionados ad hoc e que não pertençam à equipa;

- Criação de uma base de revisores da revista com as suas áreas de especialização;

- Elaborar um formulário para utilização interna da redacção com todas as "pautas" prescritas pela revista para o envio e apresentação de artigos no sentido de facilitar a verificação do seu cumprimento;

- Elaborar guias com instruçóes precisas aos revisores;

- Fixar procedimentos uniformes para atender às potenciais e/ ou reclamaçóes dos autores;

- Publicar no final de cada ano civil uma lista de revisores que estiveram ao serviço da revista, o que significa reconhecer publicamente o trabalho destes.

7. A médio e longo prazo, aconselhamos o seguinte: utilização de revisores metodológicos especializados; Aplicação de correctores de estilo que asseguram a correcção gramatical, e especialmente, a verificação da exactidão de títulos, resumos, palavras-chave e referências bibliográficas; e Formação de Revisores, criando cursos de avaliação crítica de investigação e, concomitantemente, na sequência destas formaçôes preparar e criar recursos didáctico-pedagógicos.

8. Melhorar a difusão das revistas, ou seja, a sua audiência e visibilidade através da sua difusão indirecta, da presença destas nas principais bases de dados internacionais e da sua difusão directa através das suas subscriçôes a nível nacional e internacional. Estas deverão ser mais ambiciosas e terem consciência da importância da sua internacionalização e que esta só será possível através da sua presença em bases de 
dados internacionais especializadas; 9. Deve existir uma secção fixa nestas revistas onde estas anualmente apresentem informação sobre a sua análise estatística dos conteúdos científicos da revista: número de trabalhos recebido e publicados, taxas de aceitação / rejeição e, por último, os tempos de publicação (recepção/aceitação, aceitação/publicação). Devem-se atenuar estes tempos de publicação; 10. As revistas devem exigir a apresentação dos artigos de acordo com as designadas normas de apresentação ou manuais de estilo a que estas remetem, o que vai permitir aos autores seguirem requisitos uniformes; 11 . Como mediada a curto prazo recomendamos que estas revistas, de uma maneira imediata e voluntarista/inteligente, promovam a gestão electrónica integral dos manuscritos de forma a agilizar o processo de tomada de decisões. Assim, um primeiro passo que aconselhamos as revistas a darem é que estas impulsionem, ao máximo, toda a comunicação entre a equipa editorial e os autores (carta de agradecimento, o acusar o recibo de recepção, a comunicação da primeira decisão editorial, a comunicação definitiva de aceitação ou recusa e remissão de provas) ou com os revisores (solicitação dos documentos de revisão e segunda revisão) que se realizem de forma electrónica, ou seja, via web ou via e-mail). Como mediada a longo prazo, destaca-se a importância da automatização do processo editorial e a gestão absoluta de manuscritos (apresentação, revisão, aceitação, publicação), tomando consciência nesta fase da aquisição de programas que já se encontram no mercado ou adoptando uma postura mais "caseira", desenhando a sua própria base de dados; 12. $\mathrm{Na}$ Primeira página ou Página de Título, as revistas, a curto prazo, deverão melhorar e zelar, particularmente, pela apresentaçáo de certos elementos chave dos artigos, tais como: os títulos dos artigos (abreviar de forma apurada o título da revista), nomes e apelidos completos do (s) autor (es) filiação profissional e direcçáo postal completa de cada autor, meios de contacto do (s) autor (es) (e-mail, fax e telefone), no caso do artigo ser de vários autores, apresentar o responsável da correspondência, as palavraschave, resumos e o reconhecimento de bolsas ou apoios financeiros (se existirem); 13. Relativamente à apresentaçáo dos resumos e palavras-chave recomendamos, a curto prazo, que seja exigido aos autores a apresentação destes elementos na língua inglesa, e por outro, a médio prazo aconselhamos que as revistas apresentem-nos de acordo com tesauros especializados e/ou listas de matérias; 14. Quanto à apresentação do texto propriamente dito do manuscrito, recomenda-se que as revistas exijam, nas suas instruçôes, a apresentação destes com uma determinada estrutura, podendo mesmo adoptarem, por exemplo, o modelo IMRYD; 15. Implementar, a médio prazo, e de forma capaz a profissionalização da gestão de processo editorial das revistas, ou seja, aumentar o tempo de dedicação à revista por parte do Conselho de Redacçáo e recompensá-lo, visto que uma revista científica é dirigida a profissionais com um nível de alta qualificação e perante esta realidade, é necessário que estas revistas contem com órgão de redacção (Conselho de Redacção) e de avaliação eficazes, devendo ampliar o tempo de dedicação à revistas e serem recompensados; 16. Parafraseando LópezCózar (Delgado López-Cózar, 1997), não existe qualquer dúvida de que melhorar a qualidade das revistas de CS significa que se terá que progredir muito na difusão das normas nacionais e internacionais de publicação científica relativamente à apresentação formal.

Portugal não se pode limitar a esperar que as soluçôes cheguem por parte de iniciativas supranacionais e a acção que nos parece que está a faltar é a planificação 
política a longo prazo. Na opinião de L. A. Packer (Packer, 2001), os governos através das suas políticas científicas e tecnológicas, podem jogar um papel indispensável como estão a fazer no México e no Brasil, mediante os Conselhos de Ciência e Tecnologia que estabelecem os critérios de avaliação das suas publicaçóes académicas locais e levam em diante projectos como o LATINDEX no México, a Redalyc no México, o SciELO no Brasil, e agora o SciELO Portugal, em Portugal. Acreditamos que outros trabalhos de investigação se devem juntar a este. De acordo com a nossa pesquisa, não encontrámos em Portugal outro trabalho na área das CS que aborde esta temática. Outras metodologias podem ser utilizadas, com outros critérios de avaliação, outros tipos de análise e com outros sujeitos opinando para que se aprofunde a avaliaçáo das revistas portuguesas neste campo. Mas, paralelamente a novos e potenciais estudos, a área das Ciências Sociais deve dar continuidade às publicaçóes já existentes, levando em consideração as regras básicas de qualidade para a produção de revistas científicas que são comuns a todas as ciências.

\section{Referências bibliográficas}

Baker, D. (2002). The Peer Review Process in Science Education Journals. Research in Science Education, 32, 171-180.

Beyer, Janice M. (1978, Winter). Editorial policies and practices among leading journals in four scientific fields. Sociological Quarterly, 19, 68-88.

Cardoso, Maria Manuela. (2007). As Práticas editoriais e de publicação das revistas científicas portuguesas de Ciências Sociais. [Não publicado]. Granada: Universidade de Granada.

Coe, Robert K., \& Weinstocks, Irwin. (1967). Editorial policies of major economic journals. Quarterly Review of Economics and Business, 7, 37-43.

Colaianni, L. A. (1994). Peer review in journals indexed in Index Medicus. JAMA, 272 (2), 156-158.

Costa, Rosário. (2007). O futuro das revistas científicas. e. Ciência. Retirado em Junho 21, 2007, de http://www.cienciaportugal.net//index.php?option=com_content\&task=category\&secti onid=16\&id=51\&Itemid=98 <http://www.cienciaportugal.net $/ /$ index.php?

Delgado López-Cózar, Emilio. (1997). Normas ISO de presentación de publicaciones periódicas científicas. Boletín de la ANABAD, 47 (2), 169-193.

Delgado López-Cózar, Emilio. (1998). La normalización de publicaciones científicas. Boletín de la Asociación Andaluza de Bibliotecarios, 14 (50), 53-76.

Delgado López-Cózar, Emilio. (1999). ISO standards for the presentation of scientific periodicals: Little known and little used by Spanish biomedical journals. Journal of Documentation, 55 (3), 288-309.

Delgado López-Cózar, Emilio. (2001). ?Por qué enseñar métodos de investigación en las Faculdades de Biblioteconomia y Documentación? Anales de Documentación, (4), 51-71. Retirado em Junho 21, 2007, de http://www.um.es/fccd/anales/ad04/a03metinv.pdf

Delgado López-Cózar, Emilio. (2002). La investigación en biblioteconomia y documentación. Gijón: TREA.

Delgado López-Cózar, Emilio, \& Ruiz Pérez, Rafael. (2003). Explicación de los parámetros de evaluación conforme a Normas, Manuales y prescripciones de referencia. Granada: Universidad de Granada. 
Delgado López-Cózar, Emilio, Ruiz Pérez, Rafael, \& Jiménez Contreras, Evaristo. (2007). La Edición de Revistas Científicas: Directrices, Criterios y Modelos de Evaluación. Madrid: Fundación Española para la Ciencia y la Tecnología.

Freda, M. C., \& Kearney, M. (2005). An international survey of nurse editors: roles and practices. Nurse Scholarship, 37 (1), 87-94.

Godlee, F., \& Jefferson, T. (1999). Peer Review in Health Sciences. London: BMJ Books.

Hellman, Hal. (1998). Great Feuds in Science: Ten of the Liveliest Disputes Ever (p. 40). Nova Iorque: John Wiley.

LATINDEX. (2007). Sistema Regional de Información en Linea para Revistas de América Latina, el Caribe, Espana y Portugal. Retirado em Julho 2, 2009, de http://www.latindex.unam.mx/

NP 405-1 (1994). Norma Portuguesa para referências bibliográficas: Documentos impressos. Lisboa: Instituto Português da Qualidade, Ministério da Industria e Energia.

NP 405-2 (1998). Norma Portuguesa para referências bibliográficas: Parte 2: Materiais não livro. Lisboa: Instituto Português da Qualidade, Ministério da Industria e Energia.

NP 405-3 (2000). Norma Portuguesa para referências bibliográficas: Parte 3: Documentos não publicados. Lisboa: Instituto Português da Qualidade, Ministério da Industria e Energia.

NP 405-4 (2002). Norma Portuguesa para referências bibliográficas: Parte 4: Documentos electrónicos. Lisboa: Instituto Português da Qualidade, Ministério da Industria e Energia.

OCES - Observatório da Ciência e do Ensino Superior. (2007). Ministério da Ciência, Tecnologia e Ensino Superior. Retirado em Junho 21, 2007, de http://www.oces.mctes.pt/

Packer, A. L. (2001) The SciELO Model for electronic publishing and measuring of usage and impact of Latin American and Caribbean scientific journals. Second Icsu-Unesco International Conference electronic publishing in science. Session III: responses from the scientific community. Paris: Unesco. Retirado em Abril 30, 2009, de http://www.unesco.org/science/psd/wsd03/ proceedings_sess3.htm\#s3_packer

Peters, Douglas P., \& Ceci, Stephen J. (1982). Peer review practices of psychological journals: The fate of accepted, published articles, submitted again. The Behavioural and Brain Science, 5 (2), 187-255.

Róman Róman, A. (org). (2001). La edición de revistas científicas: guía de buenos usos (p. 35-36). Madrid: Centro de Información y Documentación Científica CINDOC (CSIC). Retirado em Junho 21, 2009, de http://www.latindex.unam.mx/latindex/Documentos/Guiabu.doc

SciELO - Scientific Electronic Library Online. (2007a). Retirado em Junho 21, 2007, de http:// www.scielo.org/index.php?lang=en

SciELO Portugal. (2007b). Retirado em Junho 21, 2007, de http://www.scielo.oces.mctes. $\mathrm{pt} /$.

Weller, A. C. (1990, March 9). Editorial peer review in US medical journals. JAMA, 263 (10), 1344-1347.

Wilkes, M. S., \& Kravitz, R. (1995, August). Policies, practices, and attitudes of North American medical journal editors. Journal of General Internal Medicine, 10(8), 443-450. 


\section{Anexos}

Anexo 1 - Inventário das revistas científicas portuguesas de CS analisadas

\begin{tabular}{|c|c|c|}
\hline Título & Editor & ISSN \\
\hline Análise Psicológica & Instituto Superior de Psicologia Aplicada (ISPA) & $0870-8231$ \\
\hline Análise Social & $\begin{array}{l}\text { Instituto de Ciências Sociais. Universidade de } \\
\text { Lisboa }\end{array}$ & $0003-2573$ \\
\hline Antropologia Portuguesa & $\begin{array}{l}\text { Departamento de Antropologia. Faculdade de } \\
\text { Ciências e Tecnologia. Universidade de Coimbra }\end{array}$ & 0870-0990 \\
\hline Antropológicas & Universidade Fernando Pessoa & 0873-819X \\
\hline $\begin{array}{l}\text { A Pessoa como centro. Revista de } \\
\text { Estudos Rogerianos }\end{array}$ & $\begin{array}{l}\text { Associaçáo Portuguesa de Psicoterapia Centrada na } \\
\text { Pessoa e de Counselling }\end{array}$ & 0874-0070 \\
\hline Boletim de ciências económicas & Faculdade de Direito. Universidade de Coimbra & $0870-4252$ \\
\hline $\begin{array}{l}\text { Cadernos de biblioteconomia, } \\
\text { arquivística e documentação BAD }\end{array}$ & $\begin{array}{l}\text { Associaçáo Portuguesa de Bibliotecários, } \\
\text { Arquivistas e Documentalistas (BAD) }\end{array}$ & $0007-9421$ \\
\hline $\begin{array}{l}\text { Cidades - Comunidades e } \\
\text { Territórios }\end{array}$ & $\begin{array}{l}\text { Centro de Estudos Territoriais. Instituto de } \\
\text { Ciências do Trabalho e da Empresa (ISCTE) }\end{array}$ & $0430-5027$ \\
\hline Economia Global e Gestão & $\begin{array}{l}\text { Escola de Gestão. Instituto de Ciências do } \\
\text { Trabalho e da Empresa (ISCTE) }\end{array}$ & $0873-7444$ \\
\hline Educaçáo, sociedade \& culturas & Ediçôes Afrontamento & $0872-7643$ \\
\hline $\begin{array}{l}\text { Estudos de Economia } \\
\text { (actualmente, Portuguese } \\
\text { Economic Journal) }\end{array}$ & $\begin{array}{l}\text { Instituto Superior de Economia e Gestáo (ISEG). } \\
\text { Universidade Técnica de Lisboa }\end{array}$ & $0870-1326$ \\
\hline $\begin{array}{l}\text { Estudos de Gestáo (actualmente, } \\
\text { Portuguese Journal of } \\
\text { Management Studies) }\end{array}$ & $\begin{array}{l}\text { Instituto Superior de Economia e Gestấo (ISEG). } \\
\text { Universidade Técnica de Lisboa }\end{array}$ & $0872-5284$ \\
\hline Economia & $\begin{array}{l}\text { Universidade Católica Portuguesa. Faculdade de } \\
\text { Ciências Económicas e Empresariais }\end{array}$ & $0870-3531$ \\
\hline Economia e Sociologia & Instituto Superior Económico e Social (ISEG) & 0870-6026 \\
\hline Estudos Políticos e Sociais & $\begin{array}{l}\text { Instituto Superior de Ciências Sociais e Politicas } \\
\text { (ISEG) }\end{array}$ & $0014-1623$ \\
\hline $\begin{array}{l}\text { European Journal of Psychology } \\
\text { of education }\end{array}$ & Instituto Superior de Psicologia Aplicada (ISPA) & $0256-2928$ \\
\hline $\begin{array}{l}\text { Finisterra. Revista Portuguesa de } \\
\text { Geografia }\end{array}$ & $\begin{array}{l}\text { Centro de Estudos Geográficos. Faculdades de } \\
\text { Letras. Universidade de Lisboa } \\
\end{array}$ & $0430-5027$ \\
\hline $\begin{array}{l}\text { Garcia de Orta. Série de } \\
\text { Antropobiologia }\end{array}$ & $\begin{array}{l}\text { Instituto de Investigaçáo Científica Tropical. } \\
\text { Centro de Geografia }\end{array}$ & $0870-0168$ \\
\hline $\begin{array}{l}\text { Garcia de Orta. Série de } \\
\text { Geografia }\end{array}$ & $\begin{array}{l}\text { Instituto de Investigação Científica Tropical. } \\
\text { Centro de Geografia }\end{array}$ & $0379-9514$ \\
\hline $\begin{array}{l}\text { Geoinova. Revista do } \\
\text { Departamento de Geografia e } \\
\text { Planeamento Regional }\end{array}$ & $\begin{array}{l}\text { Departamento de Geografia e Planeamento } \\
\text { Regional }\end{array}$ & $0874-6540$ \\
\hline $\begin{array}{l}\text { Leituras: revista da Biblioteca } \\
\text { Nacional }\end{array}$ & Biblioteca Nacional de Portugal & $083-7045$ \\
\hline Media e Jornalismo & Minerva Editorial & $1645-5681$ \\
\hline Notas Económicas & Faculdade de Economia. Universidade de Coimbra & $0872-4733$ \\
\hline $\begin{array}{l}\text { Observatório. Revista da } \\
\text { Obercom }\end{array}$ & Obercom. Observatório da Comunicação & $0874-8810$ \\
\hline Organizaçóes e trabalho & $\begin{array}{l}\text { Associaçáo Portuguesa de Profissionais em } \\
\text { Sociologia Industrial, das Organizaçôes e do } \\
\text { Trabalho - APSIOT }\end{array}$ & $0871-4835$ \\
\hline
\end{tabular}




\begin{tabular}{|c|c|c|}
\hline Política Internacional & Centro Interdisciplinar de Estudos Económicos & $0873-6650$ \\
\hline Portuguese Economic Journal & Spring Verlag & $1677-982 X$ \\
\hline $\begin{array}{l}\text { Portuguese Journal of Social } \\
\text { Science }\end{array}$ & $\begin{array}{l}\text { Instituto Superior de Ciências do Trabalho do } \\
\text { Trabalho e das Empresas (ISCTE) }\end{array}$ & $1476-413 X$ \\
\hline Psicologia & Colibri & $0874-2049$ \\
\hline Psicologia, Saúde e Doenças & Sociedade Portuguesa de Psicologia da Saúde & $1654-0086$ \\
\hline Psychologica & $\begin{array}{l}\text { Faculdade de Psicologia e de Ciências da Educaçáa. } \\
\text { Universidade de Coimbra }\end{array}$ & $0871-4657$ \\
\hline Relaçóes Internacionais & $\begin{array}{l}\text { Instituto Português de Relaçóes Internacionais. } \\
\text { Universidade Nova de Lisboa }\end{array}$ & $1532-673 X$ \\
\hline Review of Financial Markets & $\begin{array}{l}\text { Centro de Investigaçáo de Mercados e Activos } \\
\text { Financeiros do ISCTE }\end{array}$ & 0874-1946 \\
\hline $\begin{array}{l}\text { Revista Crítica de Ciências } \\
\text { Sociais }\end{array}$ & $\begin{array}{l}\text { Centro de Estudos Sociais (CES). Faculdade de } \\
\text { Economia da Universidade de Coimbra. }\end{array}$ & 0254-1106 \\
\hline $\begin{array}{l}\text { Revista de Comunicação e } \\
\text { linguagens }\end{array}$ & Ediçōes Relógio d'Agua & $0870-7081$ \\
\hline $\begin{array}{l}\text { Revista de educação especial e } \\
\text { reabilitação - REER }\end{array}$ & $\begin{array}{l}\text { Universidade Técnica de Lisboa. Faculdade de } \\
\text { Motricidade Humana. Departamento de Educação } \\
\text { Especial e Reabilitaçáo }\end{array}$ & $0873-464 X$ \\
\hline $\begin{array}{l}\text { Revista de história económica e } \\
\text { social }\end{array}$ & Âncora Editora & 0870-6077 \\
\hline Revista Lusitana & $\begin{array}{l}\text { Universidade de Lisboa. Centro de Estudos } \\
\text { Geográficos }\end{array}$ & $0870-0206$ \\
\hline Revista Lusófona de Educação & $\begin{array}{l}\text { Ediçóes Universitárias Lusófonas. Universidade } \\
\text { Lusófona de Humanidades e Tecnologias }\end{array}$ & $1645-7250$ \\
\hline Revista Portuguesa de Educação & $\begin{array}{l}\text { Universidade do Minho. Instituto de Educação e } \\
\text { Psicologia. Centro de Investigação em Educaçáo }\end{array}$ & 0871-9187 \\
\hline $\begin{array}{l}\text { Revista Portuguesa e Brasileira de } \\
\text { Gestáo }\end{array}$ & $\begin{array}{l}\text { INDEG/ISCTE - Instituto para o } \\
\text { Desenvolvimento da Gestão Empresarial e } \\
\text { Fundação Getulio Vargas }\end{array}$ & $1645-4464$ \\
\hline Sociologia, Problemas e Práticas & $\begin{array}{l}\text { Centro de Investigaçáa e Estudos de Sociologia } \\
\text { (CIES). Instituto Superior de Ciências do Trabalho } \\
\text { do Trabalho e das Empresas (ISCTE) }\end{array}$ & 0873-6529 \\
\hline $\begin{array}{l}\text { Trabalhos de Antropologia e } \\
\text { Etnologia }\end{array}$ & $\begin{array}{l}\text { Sociedade Portuguesa de Antropologia e Etnologia. } \\
\text { Faculdade de Ciências da Universidade do Porto }\end{array}$ & 0304-243X \\
\hline $\begin{array}{l}\text { Universidade de Coimbra. } \\
\text { Arquivos. Boletim }\end{array}$ & Arquivo da Universidade de Coimbra & $0872-5632$ \\
\hline
\end{tabular}

Anexo 2 - Folha de Recolha de Dados (FRD)

\begin{tabular}{|l|l|l|}
\hline Título da Revista & Avaliação & Conteúdo \\
\hline Recepção e agradecimento & & \\
\hline POLÍTICA EDITORIAL E DE PUBLICAÇÃO & & \\
\hline Declaração de originalidade (náo foi publicado anteriormente) & & \\
\hline Declaração não envio simultâneo a outras revistas & & \\
\hline Declaração de autorização por cada um dos assinantes de um artigo & & \\
\hline Declaração de conflitos de interesses & & \\
\hline $\begin{array}{l}\text { Permissão de publicação por parte da instituição que financiou a } \\
\text { investigação }\end{array}$ & & \\
\hline
\end{tabular}




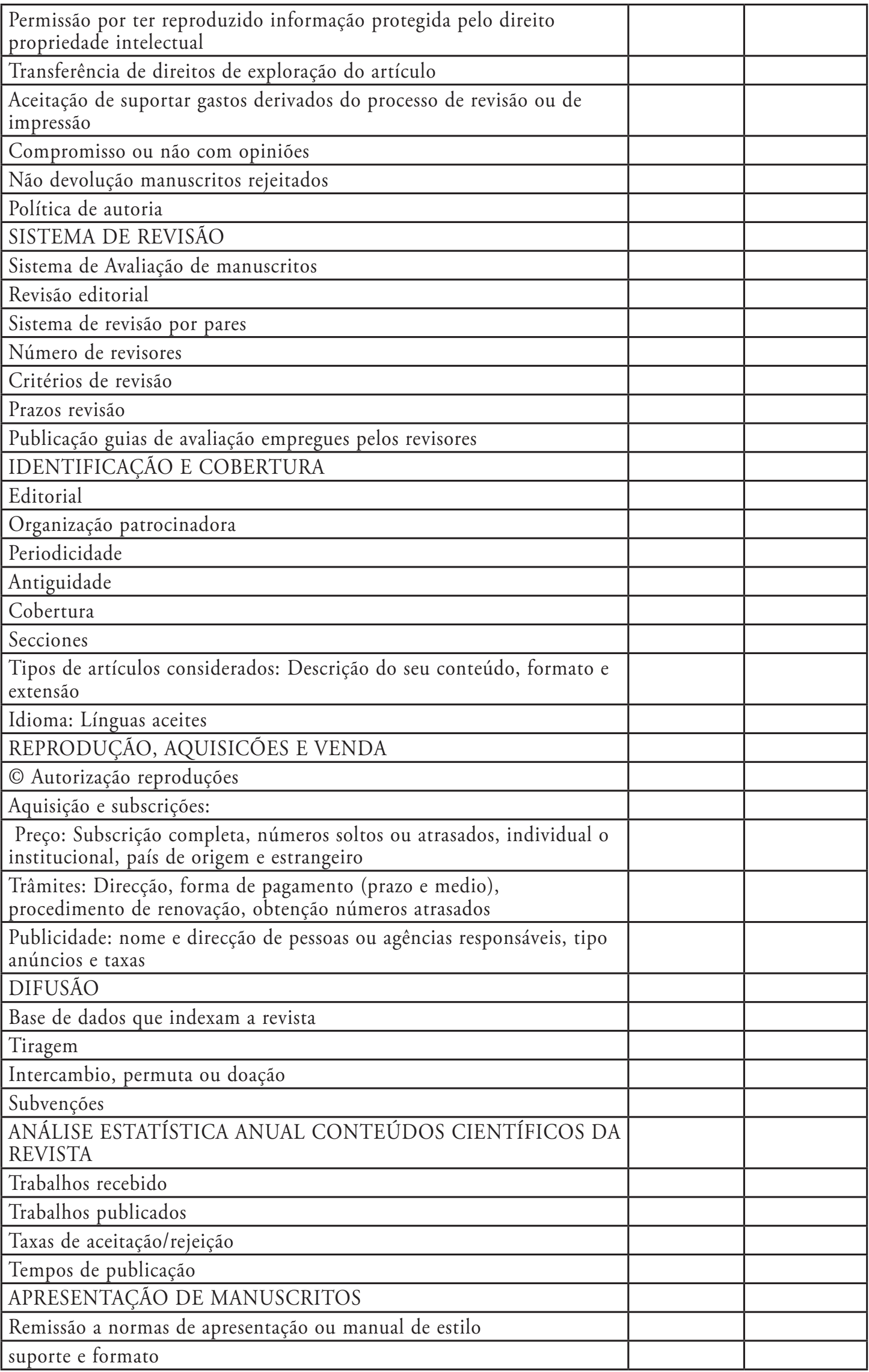




\begin{tabular}{|l|l|l|}
\hline $\begin{array}{l}\text { Informático: Formato disquete (3,5/PC o Macintosh), Tratamento de } \\
\text { textos, Número de copias Número E Nome dos ficheiros. }\end{array}$ & & \\
\hline Papel: Formato, número de cópias, una sola cara. & & \\
\hline $\begin{array}{l}\text { Estrutura física: Margens, estilo e corpo dos caracteres, tipo } \\
\text { interlineado, espaçado, longitude linhas, tipo de justificação, tipo de } \\
\text { parágrafos, numeraçáo páginas }\end{array}$ & & \\
\hline ESTILO E PARTES DO MANUSCRITO & & \\
\hline PRIMEIRA PÁGINA OU PÁGINA DE TÍTULO & & \\
\hline Título artigo & & \\
\hline Nome e apellidos completos autor(es) & & \\
\hline Filiaçáo Professional autor (es): Cargo e organismo & & \\
\hline Reconhecimento de bolsas ou apoios financeiros & & \\
\hline Direção postal completa & & \\
\hline $\begin{array}{l}\text { Noutros casos, outros meios de telecomunicaçóes ou contacto com os } \\
\text { autores: Tel. Fax, E-mail }\end{array}$ & & \\
\hline $\begin{array}{l}\text { Nos artigos assinados por vários, indicar o responsável da } \\
\text { correspondência }\end{array}$ & & \\
\hline PÁGINA DE RESUMO (RESUMO E PALABRAS-CHAVE) & & \\
\hline Tipo (Indica se é estruturado ou náo) & & \\
\hline Extensáo (Número de palavras) & & \\
\hline Palavras-chave: Número e remissão a um tesauro & & \\
\hline TEXTO & & \\
\hline Estrutura para trabalhos originais. Adopta modelo IMRYD: & & \\
\hline Explicaçáo do conteúdo de cada parte, seu estilo e características. & & \\
\hline Agradecimentos & & \\
\hline BIBLIOGRAFÍA & & \\
\hline $\begin{array}{l}\text { Sistema de citação e formato de descrição bibliográfica. Pautas } \\
\text { exemplificadoras de todos os tipos possíveis }\end{array}$ & & \\
\hline TABELAS & & \\
\hline ILUSTRAÇÕES & & \\
\hline
\end{tabular}

